\title{
The role of epithelial thickness mapping in corneal refractive surgery
}

\author{
Aleksandra Wlaź1,2, Barbara Czarnota-Nowakowska', \\ Joanna Wierzbowska ${ }^{3}$
}

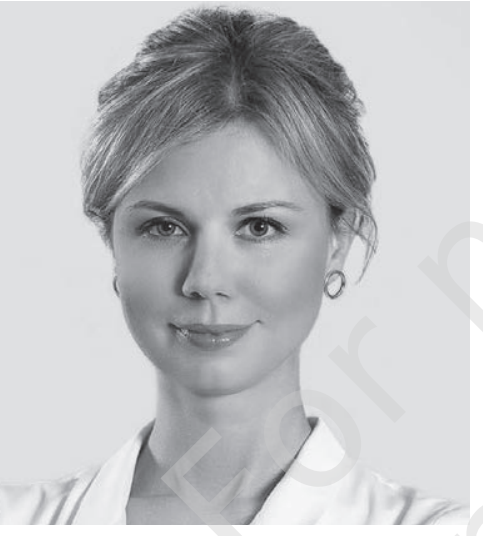

${ }^{2}$ Department of Diagnostics and Microsurgery of Glaucoma, Medical University of Lublin, Poland
Head of Department: Prof. Tomasz Żarnowski, MD, PhD

${ }^{3}$ Department of Ophthalmology, Central Clinical Hospital of the Ministry of National Defense, Military Medical Institute in Warsaw Head of Department: Prof. Marek Rękas, MD, PhD

\section{ABSTRACT}

Refractive surgery has stimulated significant progress in anterior segment imaging. Knowledge of epithelial thickness profile considerably increases the efficacy and safety of refractive procedures. This review aims to present new technologies evaluating corneal epithelial thickness and the most important clinical applications in the field of corneal refractive surgery.

Key words: epithelial thickness mapping, cornea, refractive surgery, optical coherence tomography, laser in situ keratomileusis 


\section{INTRODUCTION}

Refractive surgery has triggered significant progress in corneal and anterior segment imaging. The continuous need for increasing safety and accuracy of constantly evolving refractive procedures had inspired development of new imaging methods designed for more accurate pre- and postoperative evaluation.

Corneal topography is considered gold standard for diagnosis ectatic disorders, such as keratoconus or pellucid marginal degeneration (PMD) [1, 2]. However, despite continuously evolving methods of corneal topography imaging, the presence of irregularities in stroma may be less measurable due to changes in epithelium thickness which can mask the problem.

This review aims to provide an overview of the methods of assessment of epithelial thickness profile and to summarise clinical applications of epithelial mapping in corneal refractive surgery.

\section{Methods for epithelial thickness evaluation}

To measure epithelial thickness, very high resolution of an imaging device is needed. One of the main limitations of the Scheimpflug imaging is the low resolution of the anterior segment scans. This is the reason why Scheimpflug cameras cannot evaluate epithelial thickness profile [3].

Optical coherence tomography (OCT) and very high frequency ultrasound (VHF-US) have been the most commonly used tools for mapping the corneal epithelial thickness. In general, OCT and VHF-US have been shown to be in close agreement for epithelial thickness measurement, however, corneal epithelial thickness measurements using OCT were found to be about $4 \mu \mathrm{m}$ thinner than for VHF-US [4].

\section{Very high frequency ultrasound}

The first attempts to measure corneal epithelium were made by Reinstein et al. $[5,6]$ using VHF digital ultrasound technology. The Artemis system (ArcScan Inc, Morrison, Colo, USA) provides very high resolution ultrasound B scans of the cornea with clear delineation of epithelial surface, Bowman's layer and the posterior surface of the cornea [7]. It provides three-dimensional thickness mapping of each layer over a $10-\mathrm{mm}$ corneal diameter with approximately $1-\mu \mathrm{m}$ precision [8]. Although it still provides the most precise epithelial thickness mapping (ETM), this method is inconvenient as it requires immersion of the eye in a coupling fluid. This is the reason why Artemis had never become an instrument for routine clinical use and non-contact methods for ETM were still needed.

\section{Anterior segment optical coherence tomography}

OCT is based on low coherence interferometry using near-infrared light to produce high-resolution image of layered corneal tissue morphology $[9,10]$. So far, it has be- come the most widely used technology in everyday practice of ophthalmologists. The first OCT imaging was based on time-domain (TD-OCT). Due to its low resolution $(30 \mu \mathrm{m})$, it could not delineate epithelium [11]. Fourier domain OCT, including spectral domain OCT (SD-OCT) and swept-source OCT (SS-OCT), a newer generation of OCT is capable of acquiring scans 10-100 times faster than TD-OCT, which is associated with significantly higher resolution [12-14]. SD-OCT was launched in 2002 with RTVue (Optovue, Inc., Fremont, California, USA) with an axial and transverse resolution of $5 \mu \mathrm{m}$ and $15 \mu \mathrm{m}$, respectively. The device has a speed of 26,000 A-scans per second and a scan beam wavelength of $840 \mathrm{~nm}( \pm 10 \mathrm{~nm})$ [15]. The use of the RTVue SD-OCT for ETM was previously investigated and shown to be reliable for $\mathrm{KCN}$ patients $[16,17]$. Previous SD-OCT devices could generate maps that covered only the central $6 \mathrm{~mm}$ of the cornea. This limited their applications on peripheral diseases like PMD. The newest SD-OCT devices such as Optovue device, Avanti RTVue XR (Optovue, Inc., Fremont, California, USA) augmented corneal mapping 6-9-mm zone and increased the speed to 70,000 A-scans per second, which definitely increased the diagnostic ability of the machine [11]. The MS-39 (Costruzione Strumenti Oftalmici, Florence, Italy), an OCT instrument for only anterior segment imaging, is a hybrid technology that combines SD-OCT with Placido disk corneal topography with resolution of $3.6 \mu \mathrm{m}$ in tissue. Moreover, MS-39 is able to calculate the stromal and epithelial thickness over an $8 \mathrm{~mm}$ diameter [3, 18]. High repeatability of epithelial thickness measurements was confirmed in clinical studies [3, 19]. Other SD-OCT systems with the ability to generate epithelial thickness mapping are the corneal module for the Cirrus HD 500 (Carl Zeiss) and Revo NX (Optopol, Zawiercie, Poland). Revo NX is a new SD-OCT device that encompasses anterior and posterior segment OCT with optical biometry technology [20]. This device scans 110,000 per second with axial resolution of $5 \mu \mathrm{m}$ and transverse resolution of $18 \mu \mathrm{m}$. Epithelial maps in a $8 \mathrm{~mm}$ diameter are automatically generated by the built-in software [21]. CASIA-2 (Tomey, Aichi, Japan) and Anterion (Heidelberg Engineering), both are using sweptsource technology OCT (SS-OCT) which achieves higher penetration but lower resolution than SD-OCT. Their ETM capabilities are still under clinical trials and this function has not been commercially released yet.

\section{EPITHELIAL THICKNESS IN THE NORMAL CORNEA}

The human corneal epithelium has five to seven cell layers with central thickness of approximately $50 \mu \mathrm{m}$ to $52 \mu \mathrm{m}$ $[6,22]$. It is highly active, self-renewing layer, for which a complete turnover occurs in 5 to 7 days [22]. Reinstein et al. [6] have demonstrated a non-uniform pattern of epi- 
thelial thickness. The epithelium is significantly thicker inferiorly than superiorly and thicker nasally than temporally (fig. 1). It is suggested that blinking and friction onto the cornea may regulate the corneal epithelial thickness profile [23]. Moreover corneal epithelium plays a role in the corneal net power. It accounts for an average of $1.03 \mathrm{D}$ (range $0.55-1.85$ ) of the power of the eye at the central $2-\mathrm{mm}$ diameter zone and $0.85 \mathrm{D}$ (range $0.29-1.6$ ) at the $3.6-\mathrm{mm}$ diameter zone [24].

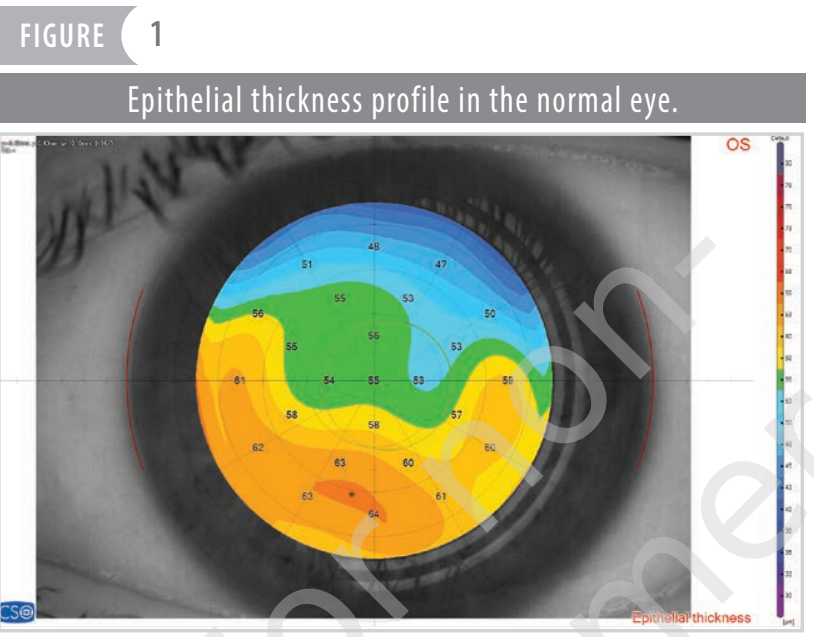

Knowledge of the epithelial thickness profile in the normal cornea may be crucial in improving the diagnosis in corneal diseases. Corneal epithelium is often non-homogeneously thinned or thickened, masking underlying stromal abnormalities. It thickens to fill depressions and thins over peaks and protrusions [25]. Remodeling of corneal epithelium occurs as a result of underlying stromal irregularities and helps to mask them. This is the reason why the topographers may overlook subclinical pathologies.

\section{APPLICATIONS OF EPITHELIAL THICKNESS MAPPING IN LASER REFRACTIVE SURGERY}

\section{Screening for ectasia risk}

It is well known that changes in the posterior corneal surface are one of the earliest signs observed in keratoconus (KC) [26, 27]. Interestingly, histopathologic studies have demonstrated epithelial thinning over the protrusion area in KC [28]. Reinstein et al. [7] have investigated epithelial thickness maps for KC screening. They found that keratoconic eye demonstrates an epithelial doughnut pattern of epithelial thinning over the cone surrounded by annulus of epithelial thickening (fig. 2). In very early $\mathrm{KC}$, epithelial compensation can mask the presence of underlying cone on front surface topography and the diagnosis of $\mathrm{KC}$ might be overlooked.
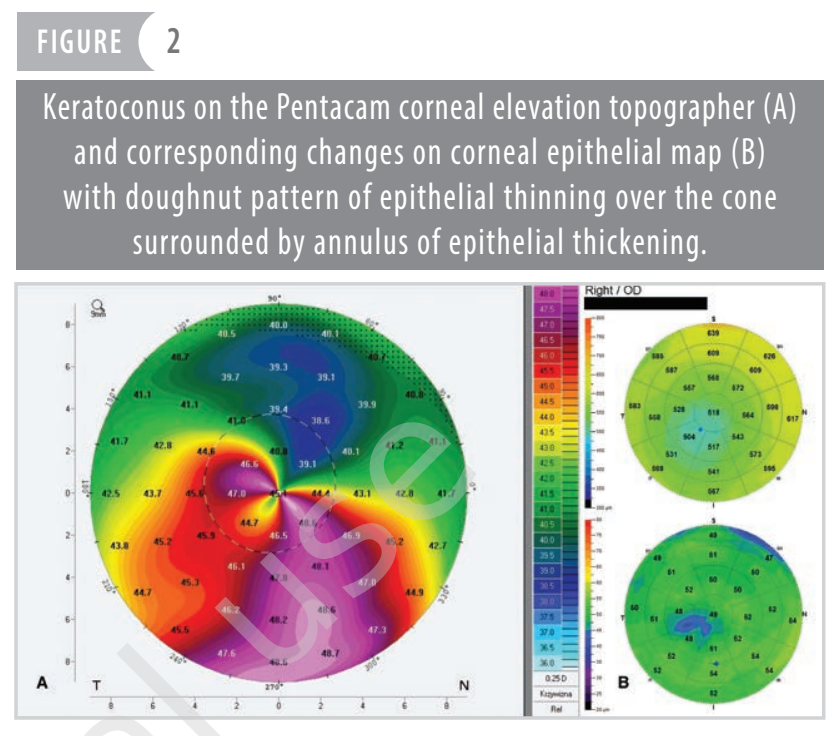

Conversely, in cases with suspicious steepening on corneal topography on axial/tangential curvature maps with corresponding epithelial thickening in area of steepening, possibility of subclinical KC can be ruled out. Contact lens-related warpage has long been known to mimic ectasia on topography maps. ETM is a useful tool to differentiate between them, since contact lens-induced epithelial remodeling is associated with epithelial thickening in the areas of topographic steepening. Conversely, in early $\mathrm{KC}$, epithelial thinning occurs in the areas of topographic steepening [29].

\section{Preoperative assessment}

Before refractive surgery, all possible pathologies of the anterior segment of the eye should be recognized. Appropriate evaluation of the corneal maps is crucial, but other conditions, i.e. epithelial dystrophies or dry eye problems should be identified either. Patients with epithelial basement membrane dystrophy (EBMD) have thicker corneal epithelium in the central and inferior region [30] (fig. 3). In dry eye patients, the superior and minimum epithelium is much thinner with a greater range of map standard deviation $[31,32]$.

\section{Postoperative assessment after refractive surgery}

Remodeling of corneal epithelium after refractive surgery depends on the kind of correction (myopia/hyperopia) and diameter of optical zone. In myopic corrections, the epithelium thickens and fills the center of the cornea, whereas in hyperopic corrections it thins in the center. Moreover, the degree of epithelial remodeling depends on ablation depth.

\section{MYOPIC CORRECTIONS}

The corneal epithelium thickens after myopic LASIK across the central $6 \mathrm{~mm}$ with maximum thickening centrally [33] (fig. 4). Reinstein et al. [6] investigated that $22 \%$ of to- 


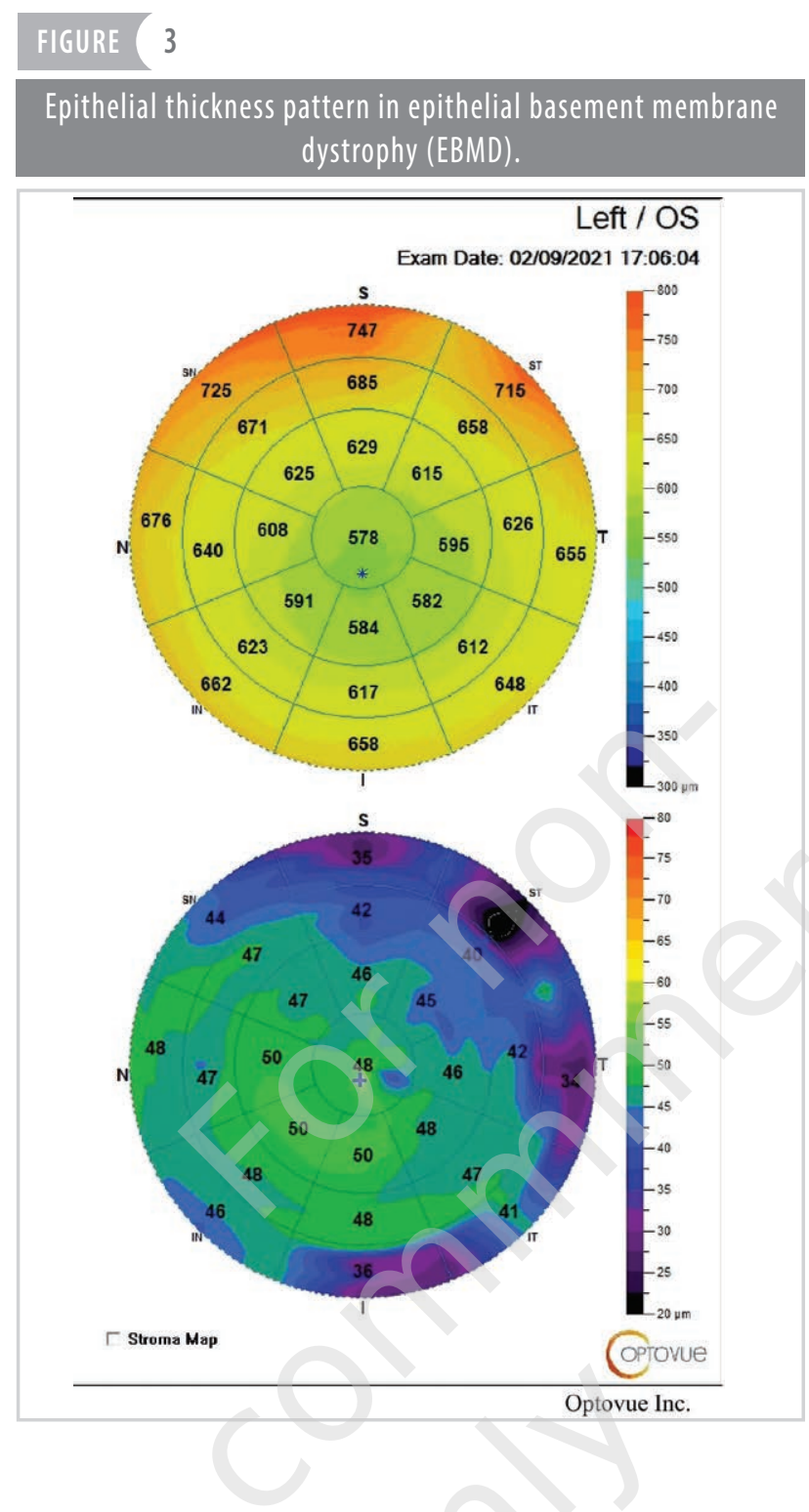

tal increase in epithelial thickness occurs during the first night postoperatively, $58 \%$ between 1 day and 1 month and $20 \%$ between 1 and 3 months, reaching stability between 3 and 12 months. Thus, the largest epithelial response was observed in the $1^{\text {st }}$ month and correlated with $-0.39 \mathrm{D}$ shift. The magnitude of epithelial thickening increases with increasing ablation depth. However, increasing the optical zone, despite removing more tissue, decreases the magnitude of epithelial thickening in the center. Reinstein et al. [34] explain it by the hypothesis of more gradual rate of change of curvature of stromal surface which leads to less thickening of epithelium in the center.

An increase in central epithelial thickness contributes to myopic regression [35-37]. Barraquer's Law of Thicknesses states that if there is a relative tissue addition in the center

\section{FIGURE ( 4}

Tangential anterior curvature (A) and corresponding epithelial thickness profile (B) after myopic correction.

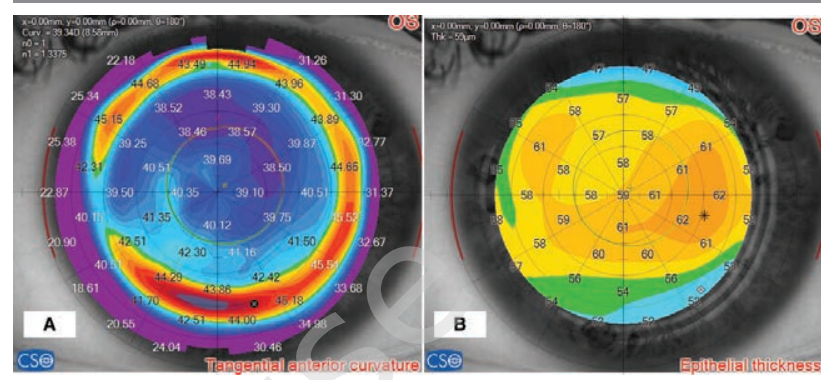

of the cornea, there will be myopic shift, whereas if there is a relative tissue removal from the center of the cornea or addition in the periphery, there will be a hyperopic refractive shift [38].

\section{HYPEROPIC CORRECTIONS}

Hyperopic ablations increase the corneal power by steepening the central corneal curvature. Epithelial thickness profile after hyperopic LASIK demonstrates thinner epithelium centrally and thicker epithelium paracentrally [39]. In high hyperopic treatments, there is a risk of significant thinning of epithelium overlying the apex. It is generally accepted that central keratometry steeper than $49 \mathrm{D}$ to $50 \mathrm{D}$ after LASIK may be associated with apical syndrome and a decrease in quality of vision [40]. However, recent studies suggest that the central epithelial thickness may be more useful indicator [39]. Reinstein et al. [39] demonstrated that the central epithelium usually thins by $2 \mu \mathrm{m}$ for every diopter of hyperopic correction. Approximately 20-25 $\mu \mathrm{m}$ of epithelial thickness is required to remain stable [41], thus knowing pre- and postoperative epithelial thickness is crucial especially in terms of retreatments [42].

\section{CONCLUSION}

In conclusion, knowledge of epithelial thickness pattern and profile of epithelial remodeling is becoming inevitable ability for every refractive surgeon. It represents a great advance in the field of anatomical and optical characterization of the eye which improves safety and accuracy of refractive procedures.

Figures: from the author's own materials. 


\section{CORRESPONDENCE}

Aleksandra Wlaź, MD, PhD

Optegra Eye Hospital, Lublin

20-719 Lublin, ul. Gęsia 5

e-mail: aleksandra.wlaz@icloud.com

\section{ORCID}

Aleksandra Wlaź - ID - http://orcid.org/0000-0001-8107-7883

Joanna Wierzbowska - ID - http://orcid.org/0000-0002-6993-7518

\section{References}

1. Maguire LJ, Bourne WM. Corneal topography of early keratoconus. Am J Ophthalmol. 1989; 108: 107-12.

2. Wilson SE, Lin DT, Klyce SD. Corneal topography of keratoconus. Cornea. 1991; 10: 2-8.

3. Schiano-Lomoriello D, Bono V, Abicca I et al. Repeatability of anterior segment measurements by optical coherence tomography combined with Placido disk corneal topography in eyes with keratoconus. Sci Rep. 2020; 10: 1124.

4. Reinstein DZ, Yap TE, Archer TJ et al. Comparison of corneal epithelial thickness measurement between Fourier-domain OCT and very high-frequency digital ultrasound. J Refract Surg. 2015; 31: 438-45.

5. Reinstein DZ, Silverman RH, Coleman DJ. High-frequency ultrasound measurement of the thickness of the corneal epithelium. Refract Corneal Surg. 1993; 9: 385-7.

6. Reinstein DZ, Archer TJ, Gobbe M et al. Epithelial thickness in the normal cornea: three-dimensional display with Artemis very high-frequency digital ultrasound. J Refract Surg. 2008; 24:571-81.

7. Reinstein DZ, Archer TJ, Gobbe M. Corneal epithelial thickness profile in the diagnosis of keratoconus. J Refract Surg. 2009; 25: 604-10.

8. Reinstein DZ, Silverman RH, Raevsky T et al. Arc-scanning very high-frequency digital ultrasound for 3D pachymetric mapping of the corneal epithelium and stroma in laser in situ keratomileusis. J Refract Surg. 2000; 16: 414-30.

9. Izatt JA, Hee MR, Swanson EA et al. Micrometer-scale resolution imaging of the anterior eye in vivo with optical coherence tomography. Arch Ophthalmol. 1994; 112: 1584-9.

10. Huang D, Swanson EA, Lin CP et al. Optical coherence tomography. Science. 1991; 254: 1178-81.

11. Hashmani N, Hashmani S, Saad CM. Wide corneal epithelial mapping using an optical coherence tomography. Invest Ophthalmol Vis Sci. 2018; 59: 1652-8.

12. Li Y, Tang M, Zhang X et al. Pachymetric mapping with Fourier-domain optical coherence tomography. J Cataract Refract Surg. 2010; 36: 826-31.

13. Christopoulos V, Kagemann L, Wollstein G et al. In vivo corneal high-speed, ultra high-resolution optical coherence tomography. Arch Ophthalmol. 2007; 125: 1027-35.

14. Sarunic MV, Asrani S, Izatt JA. Imaging the ocular anterior segment with real-time, full-range Fourier-domain optical coherence tomography. Arch Ophthalmol. 2008; 126: 537-42.

15. Sella R, Zangwill LM, Weinreb RN et al. Repeatability and reproducibility of corneal epithelial thickness mapping with spectral-domain optical coherence tomography in normal and diseased cornea eyes. Am J Ophthalmol. 2019; 197: 88-97.

16. Prakash G, Agarwal A, Jacob S et al. Comparison of fourier-domain and time-domain optical coherence tomography for assessment of corneal thickness and intersession repeatability. Am J Ophthalmol. 2009; 148: 282-90.

17. Tang M, Li Y, Chamberlain W et al. Differentiating keratoconus and corneal warpage by analyzing focal change patterns in corneal topography, pachymetry, and epithelial thickness maps. Invest Ophthalmol Vis Sci. 2016; 57: OCT544-OCT9.

18. Savini G, Schiano-Lomoriello D, Hoffer KJ. Repeatability of automatic measurements by a new anterior segment optical coherence tomographer combined with Placido topography and agreement with 2 Scheimpflug cameras. J Cataract Refract Surg. 2018; 44: 471-8.

19. Vega-Estrada A, Mimouni M, Espla E et al. Corneal epithelial thickness intrasubject repeatability and its relation with visual limitation in keratoconus. Am J Ophthalmol. 2019; 200: 255-62.

20. Kanclerz P, Hoffer KJ, Rozema JJ et al. Repeatability and reproducibility of optical biometry implemented in a new optical coherence tomographer and comparison with a optical low-coherence reflectometer. J Cataract Refract Surg. 2019; 45: 1619-24.

21. LiY, Gokul A, McGhee C et al. Repeatability of corneal and epithelial thickness measurements with anterior segment optical coherence tomography in keratoconus. PLoS One. 2021; 16: e0248350.

22. Hanna C, O'Brien JE. Cell production and migration in the epithelial layer of the cornea. Arch Ophthalmol. 1960; 64: 536-9.

23. Reinstein DZ, Silverman RH, Trokel SL et al. Corneal pachymetric topography. Ophthalmology. 1994; 101: 432-8.

24. Simon G, Ren Q, Kervick GN et al. Optics of the corneal epithelium. Refract Corneal Surg. 1993; 9: 42-50.

25. Silverman RH, Urs R, Roychoudhury A et al. Epithelial remodeling as basis for machine-based identification of keratoconus. Invest Ophthalmol Vis Sci. 2014; 55: 1580-7.

26. Khachikian SS, Belin MW. Posterior elevation in keratoconus. Ophthalmology. 2009; 116(4): 816, 816.e1. 
27. de Sanctis U, Loiacono C, Richiardi L et al. Sensitivity and specificity of posterior corneal elevation measured by Pentacam in discriminating keratoconus/subclinical keratoconus. Ophthalmology. 2008; 115: 1534-9.

28. Scroggs MW, Proia AD. Histopathological variation in keratoconus. Cornea. 1992; 11: 553-9.

29. Schallhorn JM, Tang M, Li Y et al. Distinguishing between contact lens warpage and ectasia: usefulness of optical coherence tomography epithelial thickness mapping. J Cataract Refract Surg. 2017; 43: 60-6.

30. Buffault J, Zeboulon $\mathrm{P}$, Liang $\mathrm{H}$ et al. Assessment of corneal epithelial thickness mapping in epithelial basement membrane dystrophy. PLoS One. 2020; 15: e0239124.

31. Cui X, Hong J, Wang F et al. Assessment of corneal epithelial thickness in dry eye patients. Optom Vis Sci. 2014; 91: $1446-54$.

32. Salomao MQ, Hofling-Lima AL, Lopes BT et al. Role of the corneal epithelium measurements in keratorefractive surgery. Curr Opin Ophthalmol. 2017; 28: 326-36.

33. Reinstein DZ, Archer TJ, Gobbe M. Change in epithelial thickness profile 24 hours and longitudinally for 1 year after myopic LASIK: three-dimensional display with Artemis very high-frequency digital ultrasound. J Refract Surg. 2021; 28: 195-201.

34. Reinstein DZ, Archer TJ, Gobbe M. Rate of change of curvature of the corneal stromal surface drives epithelial compensatory changes and remodeling. J Refract Surg. 2014; 30: 799-802.

35. Lohmann CP, Guell JL. Regression after LASIK for the treatment of myopia: the role of the corneal epithelium. Semin Ophthalmol. 1998; 13: 79-82.

36. Gauthier CA, Holden BA, Epstein D et al. Role of epithelial hyperplasia in regression following photorefractive keratectomy. Br J Ophthalmol. 1996; 80: 545-8.

37. Lohmann CP, Reischl U, Marshall J. Regression and epithelial hyperplasia after myopic photorefractive keratectomy in a human cornea. J Cataract Refract Surg. 1999; 25: 712-5.

38. Reinstein DZ, Srivannaboon S, Gobbe M et al. Epithelial thickness profile changes induced by myopic LASIK as measured by Artemis very high-frequency digital ultrasound. J Refract Surg. 2009; 25: 444-50.

39. Reinstein DZ, Archer TJ, Gobbe M et al. Epithelial thickness after hyperopic LASIK: three-dimensional display with Artemis very high-frequency digital ultrasound. J Refract Surg. 2010; 26: 555-64.

40. Varley GA, Huang D, Rapuano CJ et al. LASIK for hyperopia, hyperopic astigmatism, and mixed astigmatism: a report by the American Academy of Ophthalmology. Ophthalmology. 2004; 111: 1604-17.

41. Vinciguerra P, Camesasca FI, Morenghi E et al. Corneal apical scar after hyperopic excimer laser refractive surgery: long-term follow-up of treatment with sequential customized therapeutic keratectomy. J Refract Surg. 2018; 34: 113-20.

42. Hwang ES, Schallhorn JM, Randleman JB. Utility of regional epithelial thickness measurements in corneal evaluations. Surv Ophthalmol. 2020; 65: 187-204.

Authors' contributions:

All authors contributed equally to the article.

Conflict of interest:

None.

Financial support:

None.

Ethics:

The content presented in the article complies with the principles of the Helsinki

Declaration, EU directives and harmonized requirements for biomedical journals. 